\title{
Extensive polymorphism and geographical variation at a positively selected MHC class II B gene of the lesser kestrel (Falco naumanni)
}

\author{
MIGUEL ALCAIDE, ${ }^{*}$ SCOTT V. EDWARDS,† JUAN J. NEGRO ${ }^{*}$ DAVID SERRANO* and \\ JOSÉ L. TELLA* \\ *Estación Biológica de Doñana (CSIC) Pabellón de Perú, Avenida Maria Luisa s/n 41013, Sevilla, Spain, +Department of Organismic \\ and Evolutionary Biology, Harvard University, 26 Oxford Street, Cambridge, MA 02138, USA
}

\begin{abstract}
Understanding the selective forces that shape genetic variation in natural populations remains a high priority in evolutionary biology. Genes at the major histocompatibility complex (MHC) have become excellent models for the investigation of adaptive variation and natural selection because of their crucial role in fighting off pathogens. Here we present one of the first data sets examining patterns of MHC variation in wild populations of a bird of prey, the lesser kestrel, Falco naumanni. We report extensive polymorphism at the second exon of a putatively functional MHC class II gene, Fana-DAB*1. Overall, 103 alleles were isolated from 121 individuals sampled from Spain to Kazakhstan. Bayesian inference of diversifying selection suggests that several amino acid sites may have experienced strong positive selection $(\omega=4.02$ per codon). The analysis also suggests a prominent role of recombination in generating and maintaining MHC diversity $(\rho=4 N c=0.389$ per codon, $\theta=0.017$ per codon). Both the Fana-DAB ${ }^{*} 1$ locus and a set of eight polymorphic microsatellite markers revealed an isolation-by-distance pattern across the Western Palaearctic $(r=0.67 ; P=0.01$ and $r=0.50 ; P=0.04$, respectively). Nonetheless, geographical variation at the MHC contrasts with relatively uniform distributions in the frequencies of microsatellite alleles. In addition, we found lower fixation rates in the MHC than those predicted by genetic drift after controlling for neutral mitochondrial sequences. Our results therefore underscore the role of balancing selection as well as spatial variations in parasitemediated selection regimes in shaping MHC diversity when gene flow is limited.
\end{abstract}

Keywords: adaptive variation, balancing selection, bird of prey, conservation genetics, population genetics,

Introduction

Genetic diversity is widely considered essential for the evolutionary and adaptive potential of populations and species. Many studies have therefore aimed at providing insights into genome-wide diversity using a relatively short array of neutral loci (reviewed by Coltman \& Slate 2003; DeWoody \& DeWoody 2005). Although variation at supposedly neutral DNA markers such as microsatellites or mitochondrial DNA (mtDNA) has great potential for

Correspondence: Miguel Alcaide, Fax: +34 9546211 25;

E-mail: malcaide@ebd.csic.es inferring population connectivity and relatedness (e.g. Paetkau et al. 1995; Godoy et al. 2004; Martínez-Cruz et al. 2004; Alcaide etal. 2005; Fredsted et al. 2005), their suitability for detecting adaptive variation and as surrogates for genetic variation in fitness-related loci is limited (e.g. Crandall et al. 2000; Aguilar et al. 2004; Jarvi et al. 2004). Furthermore, local adaptation often requires restricted gene flow, and thus, investigating variation at genes under selection may be useful for unravelling population subdivision as well (e.g. Miller \& Whitler 1997; Miller et al. 1997, 2001). The major histocompatibility complex (MHC) has become an excellent model for the investigation of adaptive variation in vertebrates (see 
recent reviews by Sommer 2005; Piertney \& Oliver 2006). The MHC is a multigene family involved in the development of adaptive immune responses against pathogens (Klein 1986). MHC genes encode cell-surface glycoproteins that bind and present short peptides (i.e. antigens) to specialized cells of the immune system in order to trigger appropriate immune reactions including antibody production or destruction of antigen-presenting cells. Genetic variation at MHC genes largely determines what foreign peptides an individual is capable of responding to, and thus, is thought to influence individual fitness and long-term survival of populations (Hughes 1991; Hughes \& Nei 1992).

Several evolutionary mechanisms have been suggested to generate and maintain extraordinary levels of polymorphism at the MHC (e.g. Robinson et al. 2000). Thus, some studies have documented a major role of intragenic recombination and gene conversion against de novo point mutations (e.g. Richman et al. 2003). On the other hand, two main types of balancing selection, 'heterozygote advantage' and 'frequency-dependent selection', are also thought to be important in maintaining the high levels of MHC variability needed to counteract selection pressures imposed by pathogens (Hedrick 1999; Bernatchez \& Landry 2003). Additionally, other nonmutually exclusive modes of selection have dealt with spatial and/or temporal variations in parasite selection regimes (Hill 1991), MHC-dependent mate choice (Penn \& Potts 1999) and maternal-foetal interactions (Clarke \& Kirby 1966; Edwards \& Hedrick 1998).

The usually highly polymorphic second exon of MHC class II B genes has been widely studied in vertebrates because this locus encodes the functionally important peptide-binding region (PBR) involved in the immune response against bacteria and parasites (e.g. Musolf et al. 2004; Bos \& DeWoody 2005; Miller et al. 2005; Wegner et al. 2006). In birds, most studies of the MHC have focused mainly on galliform species or passerines (Edwards et al. 1998; Witzell et al. 1999; Ye et al. 1999; Bonneaud et al. 2004; Jarvi et al. 2004), with few examples of other avian groups (Bollmer et al. 2007; Ekblom et al. 2007). In this respect, the isolation of avian MHC genes has been traditionally assumed to be laborious and time-consuming because of the substantial variation in gene organization even between closely related species. Furthermore, many species possess multiple MHC loci (e.g. Westerdahl et al. 2004), and concerted evolution among paralogous genes (e.g. Edwards et al. 1995; Witzell et al. 1999) has challenged the construction of locus-specific primers. However, a recent and extensive characterization of MHC class II B genes in birds of prey showed that the structure of genes from species belonging to the same raptor family is quite well conserved (Alcaide et al. 2007). Although concerted evolution precluded the design of locus-specific primers in several species (see Alcaide et al. 2007), the number of gene copies was generally low (1-3). At first sight, the complexity and diversity of MHC genes of birds of prey would resemble that of the widely studied chicken MHC, which appears to be small and compact, containing only enough expressed genes to ensure resistance against common pathogens (i.e. 'minimal essential MHC hypothesis', Kaufman \& Salomonsen 1997). However, the use of polymerase chain reaction (PCR) approaches in this previous study cannot dismiss an underestimation of the number of gene copies in a multigene family (e.g. Wagner et al. 1994). Among the raptor species investigated, those belonging to the genus Falco provided the best chance for investigating patterns of MHC variation at single polymorphic and positively selected MHC loci.

The lesser kestrel Falco naumanni is one of the most widely studied bird species. During the last century, habitat transformations led to the extinction of the species from several locations of its breeding range in Eurasia, practically disappearing in others (Biber 1990). Changes in land use and agricultural practices have been implicated as the main causes of population decline (Tella et al. 1998) of this habitat-specialist falcon inhabiting steppe and pseudosteppe ecosystems (Cramp \& Simmons 1980; Ferguson-Lees \& Christie 2001). As a result, the breeding range of the philopatric lesser kestrel became more patchy. Genetic divergence among fragments may be thus expected to follow an isolation-by-distance pattern that would be in agreement with strong philopatry and restricted dispersal over short distances (see Negro et al. 1997; Serrano et al. 2001; Serrano \& Tella 2003). Such restrictions in gene flow might predict an increase in the chance for local adaptations that could be reflected in functionally important genes such as those belonging to the MHC. On the other hand, the smaller population sizes brought on by population decline could thwart the effects of selection, leaving a more random pattern.

Our aim in this study, one of the first examining $\mathrm{MHC}$ diversity in wild populations of a bird of prey, was of comparing patterns of variation at MHC loci and supposedly neutral markers (microsatellites and mtDNA) in order to investigate the extent of local adaptations at evolutionary relevant genes when gene flow is limited. Our study is geographically broad, including several populations across Eurasia, from Spain to Kazakhstan. As far as we know, geographical variation in MHC genes has only been studied previously in a few bird species: the great snipe (Gallinago media, Ekblom et al. 2007), the red grouse (Lagopus lagopus scoticus, Piertney 2003), South Island robin (Petroica australis australis, Miller \& Lambert 2004a) and the little greenbul (Andropadus virens, Aguilar et al. 2006). Besides providing valuable data concerning diversity at functially important genes and conclusion on the relevance of the MHC, this study also assesses the suitability of MHC 
Table 1 Sampled populations and number of birds typed at microsatellites ( $\mu$ sats), mtDNA control region sequences (CR) and Fana- DAB 1 (MHC). The most abundant MHC alleles at each location are indicated. MHC alleles were named following the nomenclature recommended by Klein et al. (1990)

\begin{tabular}{lllll}
\hline Population (code) & $\begin{array}{l}\text { No. of birds typed } \\
\mu \text { sats/CR/MHC }\end{array}$ & $\begin{array}{l}\text { Year of } \\
\text { sampling }\end{array}$ & $\begin{array}{l}\text { No. of MHC } \\
\text { alleles }\end{array}$ & Most frequent MHC alleles \\
\hline SW-Spain (SWS) & $69 / 8 / 25$ & 2002 & 33 & Fana2 (20\%) Fana $19(12 \%)$ \\
CW-Spain (CWS) & $76 / 0 / 0$ & 2002 & - & - \\
NE-Spain (NES) & $68 / 8 / 25$ & 2002 & 28 & Fana2 (16\%) Fana $19(16 \%)$ \\
France (FRA) & $26 / 0 / 16$ & 2002 & 18 & Fana2 (15\%) Fana $1(12.5 \%)$ \\
Italy (ITA) & $26 / 8 / 16$ & 2003 & 18 & Fana2 (29\%) Fana $1(12.5 \%)$ Fana3 (12.5\%) \\
Greece (GRE) & $21 / 8 / 16$ & 2003 & 22 & Fana2 (12.5\%) Fana $1(9.3 \%)$ Fana29 $(9.3 \%)$ \\
Israel (ISR) & $34 / 16 / 17$ & 2003 & 20 & Fana36 (15\%) Fana $22(11 \%)$ \\
Kazakhstan (KAZ) & $7 / 0 / 7$ & 2003 & 12 & Fana77 (14\%) \\
\hline
\end{tabular}

genes as potential genetic markers to establish the origin of vagrant or captive individuals, undoubtedly, one of the most exciting scopes in molecular ecology.

\section{Materials and methods}

\section{Study species and populations}

The lesser kestrel (Aves: Falconidae) is a small migratory falcon whose breeding range covers mid-latitude and low altitudes of Eurasia. Here, this facultatively colonial falcon can be found in human structures holding up to 100 breeding pairs when they are surrounded by agricultural land. Lesser kestrels are known to winter in the savannah and grass plains of Africa, with the most numerous aggregations recorded in the southern region of the continent (Cramp \& Simmons 1980; Ferguson-Lees \& Christie 2001).

We investigated geographically distinct breeding populations of lesser kestrels across Eurasia: southwestern Spain (SWS), central-western Spain (CWS), northeastern Spain (NES), France (FRA), Italy (ITA), Greece (GRE), Israel (ISR) and Kazakhstan (KAZ) (see Table 1, Fig. 1). Only one individual per nest was analysed, and therefore, individuals were presumably unrelated. Number of individuals analysed per population is shown in Table 1. Birds were caught during the 2002 and 2003 breeding season, and thus, our estimates are unlikely to be influenced by temporal variation in selection patterns. Blood samples from Iberian birds were preserved in absolute ethanol, and feathers pulled from the birds' back were stored in paper envelopes or plastic bags and kept at $4{ }^{\circ} \mathrm{C}$ when sampling individuals from the remainder breeding distribution. The DNA purification protocol we used follows that described by Gemmell \& Akiyama (1996). Blood and feather tips were digested by incubation with proteinase $K$ for at least $3 \mathrm{~h}$. DNA purification was carried out by using $5 \mathrm{M} \mathrm{LiCl}$, organic extraction with chloroform-isoamylic alcohol (24:1)

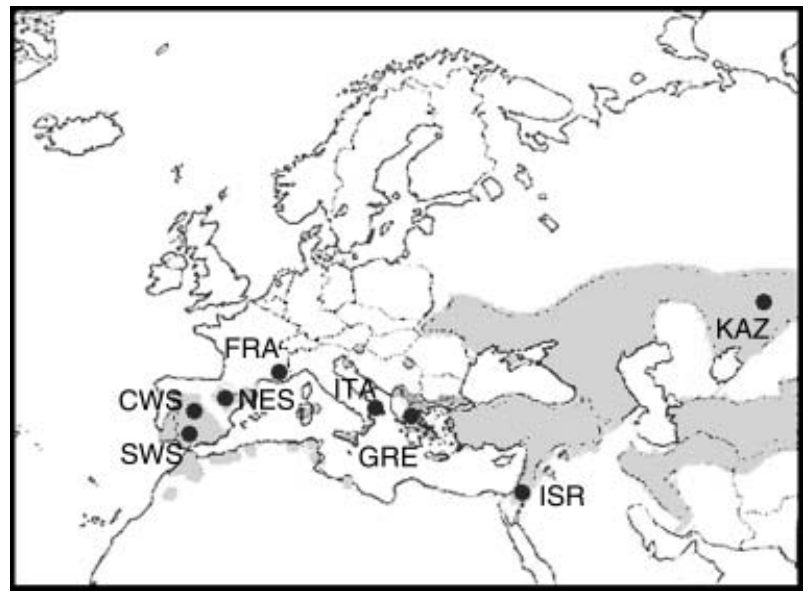

Fig. 1 Breeding distribution of the lesser kestrel in the Western Palearctic (grey areas). Populations investigated in this study are indicated by black dots.

and DNA precipitation with absolute ethanol. Pellets obtained were dried and washed twice with $70 \%$ ethanol, and later stored at $-20^{\circ} \mathrm{C}$ in $0.1 \mathrm{~mL}$ of TE buffer.

\section{Microsatellite genotyping}

We amplified nine microsatellites that were isolated originally in the peregrine falcon Falco peregrinus (Fp5, Fp13, Fp31, Fp46-1, Fp79-4, Fp89, Fp107 CL58 and C1347; Nesje et al. 2000; see Appendix). For each locus, PCR was carried out in a PTC-100 Programmable Thermal Controller (MJ Research) using the following PCR profile: 35 cycles of $40 \mathrm{~s}$ at $94{ }^{\circ} \mathrm{C}, 40 \mathrm{~s}$ at $55^{\circ} \mathrm{C}, 40 \mathrm{~s}$ at $72{ }^{\circ} \mathrm{C}$ and finally, $4 \mathrm{~min}$ at $72{ }^{\circ} \mathrm{C}$. Each $11 \mu \mathrm{L}$ reaction contained $0.2 \mathrm{U}$ of Taq polymerase (Bioline), $1 \times$ PCR manufacturersupplied buffer, $1.5 \mathrm{~mm} \mathrm{MgCl}, 0.02 \%$ gelatine, $0.12 \mathrm{~mm}$ of each dNTP, 5 pM of each primer and, approximately, $10 \mathrm{ng}$ of genomic DNA. Forward primers were 5'-end labelled with HEX, TET or 6-FAM. Amplified fragments were 
resolved on an ABI PRISM 310 Genetic Analyser (Applied Biosystems). Conformity to Hardy-Weinberg expectations and linkage disequilibrium was analysed using GENEPOP (Raymond \& Rousset 1995).

\section{Mitochondrial DNA sequencing}

We amplified a 262-bp fragment (excluding primers) of the mitochondrial control region (CR) that has previously been shown to contain a high number of polymorphic sites in the Falco species (e.g. Nittinger et al. 2007). The selected fragment extends from the central part of the CR to the repetitive section adjacent to the trRNA (positions 15 814-16 014 in F. peregrinus, Accession no. AF090338). Overall, mtDNA samples from16 birds hatched in Spain, 16 birds from Italy and Greece as well as 16 birds from Israel were sequenced (Table 1). Previous analyses utilizing cytochrome $b$ sequences documented a strong pattern of genetic differentiation between Asian and Mediterranean populations of lesser kestrels (Wink et al. 2004). Thus, we believe it unnecessary to amplify control regions sequences from the birds sampled in Kazakhstan. The PCR in these experiments was carried out using primers CRFalF1: 5'-GCTTCACAGGTGACCCTTC-3' and CRFalR1: 5'-GATGTGAATTTTGGCGGG-3'. The PCR profile consisted of 35 cycles of $40 \mathrm{~s}$ at $94{ }^{\circ} \mathrm{C}, 40 \mathrm{~s}$ at $52^{\circ} \mathrm{C}, 40 \mathrm{~s}$ at $72{ }^{\circ} \mathrm{C}$ and finally, $4 \mathrm{~min}$ at $72{ }^{\circ} \mathrm{C}$. Each $20 \mu \mathrm{L}$ reaction contained $0.2 \mathrm{U}$ of Taq polymerase (Bioline), $1 \times$ PCR manufacturer-supplied buffer, $1.5 \mathrm{~mm} \mathrm{MgCl}_{2}, 0.02 \%$ gelatine, $0.12 \mathrm{~mm}$ of each dNTP and 5 pM of each primer. Since the yield of PCR products was generally low when amplifying mitochondrial sequences from feather tips, we performed post re-amplifications to increase the concentration of the PCR template to be sequenced as well as negative controls in the PCR experiments in order to detect contaminations. Sequencing reactions were carried out using the BigDye 1.1 Terminator technology, and labelled fragments were subsequently resolved in a 3100 automated sequencer (Applied Biosystems). The co-amplification of nuclear copies of mitochondrial sequences (numts) was detected through the analysis of sequencing chromatograms. Some individuals showing one or two double peaks were discarded and substituted by new individuals until we reached the sample sizes given above. Since avian erythrocytes are enriched for nuclear DNA and depleted for mitochondrial DNA, the co-amplification of putative numts was more frequently found in DNA extracted from blood samples (four cases out of 20 individuals analysed) than in DNA extracted from feather tips (two cases out of 34 individuals analysed). Unambiguous sequences were aligned using the software BIOEDIT (Hall 1999) and basic statistics of mtDNA diversity, including nucleotide and haplotype diversity, were calculated in DNASP (Rozas et al. 2003).

\section{MHC class II genotyping}

The entire second exon of an MHC class II B locus, which we here designate as Fana-DAB ${ }^{*}$, was amplified using primers Fal2FC (5'-CCTCCCTGTACAAACAGAG-3') and Fal2RC (5'-GTGGCACTGGGAAACSTG-3'), which sit in the flanking introns 1 and 2, respectively (see Alcaide $e t$ al. 2007 for more details). Overall, 121 kestrels were genotyped from Spain to Kazakhstan (Table 1). The PCR was carried out in a PTC-100 Programmable Thermal Controller (MJ Research) using the following PCR profile: 1 cycle of $4 \mathrm{~min}$ at $94{ }^{\circ} \mathrm{C}, 35$ cycles of $40 \mathrm{~s}$ at $94^{\circ} \mathrm{C}, 40 \mathrm{~s}$ at $56^{\circ} \mathrm{C}, 40 \mathrm{~s}$ at $72{ }^{\circ} \mathrm{C}$ and finally, $4 \mathrm{~min}$ at $72{ }^{\circ} \mathrm{C}$. Each $25 \mu \mathrm{L}$ reaction contained $0.4 \mathrm{U}$ of Taq polymerase (Bioline), $1 \times$ PCR manufacturersupplied buffer, $1.5 \mathrm{~mm} \mathrm{MgCl}_{2}, 0.02 \%$ gelatine, $0.12 \mathrm{~mm}$ of each dNTP, $10 \mathrm{pm}$ of each primer, 5\% DMSO and, approximately, $25 \mathrm{ng}$ of genomic DNA. Investigation of variation at $\mathrm{MHC}$ loci requires separating the different PCR amplification products, either because of the possibility of amplifying more than one locus, or because individuals are likely to be heterozygous at many sites in these loci. After PCR clean-up in Microcon centrifuge tubes (Millipore), PCR products were cloned into bacterial plasmids using the PGEM-T easy vector system II (Promega). Clones were screened for the expected insert size in $1.5 \%$ agarose gels by running a second PCR with M13 primers. Six to eight positive clones per individual were selected at random for sequencing analysis. Sequencing reactions were carried out using the BigDye 1.1 Terminator technology and labelled fragments were subsequently resolved in a 3100 automated sequencer (Applied Biosystems).

MHC class II sequences were aligned and edited using BIOEDIT 7.0.5.2 (Hall 1999). Following Edwards et al. (1995), rare sequences found only once and differing by less than $3 \mathrm{bp}$ from a redundant sequence of the same PCR product were considered artefacts of PCR errors and were assumed to have already been sampled. Since recombination of cloned PCR products is an additional source of artefacts (Bradley \& Hillis 1996), direct sequencing of uncloned PCR products was used to check for agreement of polymorphic sites with cloned sequences. All alleles found only in one individual were verified by performing a second typing of that individual. Polymorphism statistics were generated using the software DNASP (Rozas et al. 2003). Putative amino acid sequences were obtained after alignment to the chicken B-LBII (Zoorob et al. 1990).

\section{Estimating diversifying selection in the presence of recombination}

There are many tests for selection on MHC genes, each appropriate for different timescales over which selection acts (reviewed by Garrigan \& Hedrick 2003). The selection 
parameter $\omega$ measures the ratio between nonsynonymous substitutions $\left(\mathrm{d}_{\mathrm{N}}\right)$ and synonymous substitutions $\left(\mathrm{d}_{\mathrm{S}}\right)$ along coding sequences. An excess of nonsynonymous substitutions over synonymous substitutions is related to positive selection, where $\omega>1$. By contrast, functional constraints in protein sequences are indicated by values of $\omega<1$. Maximum-likelihood methods have been widely used to test for the presence of codons affected by positive selection and to identify those sites (e.g. Yang 2000). Nevertheless, the use of phylogenetic methods to identify sites experiencing diversifying selection in the presence of high levels of recombination is believed to cause high numbers of false positives (Anisimova et al. 2003). In this respect, high recombination rates at the MHC have been commonly documented (e.g. Richman et al. 2003; Edwards \& Dillon 2004; Miller \& Lambert 2004b), and consequently, $\omega$ values might be overestimated. We therefore used the recently developed program OMEGAMAP (Wilson \& McVean 2006), which permits inference of positive selection in the presence of recombination. OMEGAMAP employs a Bayesian population genetics approximation to the coalescent theory that co-estimates the selection parameter $\omega$ and the recombination rate $\left(\rho=4 N_{e} c\right)$ along the sequence in order to incorporate evolutionary uncertainty. Positional variation in $\omega$ across exon 2 was investigated using a sliding window of 10 codons (approximately $10 \%$ of the total, see Wilson $\&$ McVean 2006). Analyses were conducted using an objective set of priors (i.e. those that do not represent any previous information about the values of different parameters considered in the model). Following the authors' recommendation (see more details in Wilson \& McVean 2006), the probable values of the mutation rate $(\mu)$ and the transition/transversion rate ratio $(\kappa)$ were adjusted to follow improper inverse distributions (starting values for $\mu$ and $\kappa$ were set at 0.1 and 3.0, respectively), and the selection parameter $(\omega)$ and the recombination rate $(\rho)$ were adjusted to follow inverse distributions in the range between 0.01 and 100. Means for $\omega$, $\rho$, and the population mutation rate $(\theta=4 N \mu)$ per codon were calculated using the posterior distributions generated with the objective prior set. Two Markov chain Monte Carlo tests were run for 500000 iterations, with a 50000 iteration burn-in. After paired chains were checked for convergence (i.e. two independent runs should match within an acceptable degree of error when comparing in a plot the mean and higher and lower 95\% highest posterior densities for $\omega$ against codon position), they were merged to infer posterior distributions over $\omega$.

\section{Estimates of population differentiation}

The extent of population differentiation at supposedly neutral microsatellite markers was calculated according to the traditional $F_{\mathrm{ST}}$ estimate using the software GENETIX
4.04 (Belkhir et al. 1996-2004). On the other hand, the substantial variability commonly found at MHC genes has highlighted the statistical inadequacy of analysing individual DNA or amino acid sequences for some problems. This fact has been addressed, for instance in humans, by grouping alleles into supertypes attending to shared binding motifs (e.g. Lund et al. 2004). Although only a few amino acid differences are known to confer different degrees of protection against pathogens (e.g. Hill 1998; Froeschke \& Sommer 2005; Bonneaud et al. 2006), closely related alleles are thought to have similar peptidebinding properties (e.g. Trachtenberg et al. 2003). Thus, the relative frequencies of certain allelic lineages, rather than individual alleles, may reflect adaptation to local pathogen communities. We therefore calculated the nucleotidesequence-based estimate of genetic differentiation $K_{\mathrm{ST}}$ (Hudson et al. 1992) for MHC and mitochondrial sequences using the software DNASP (Rozas et al. 2003). In addition, clustering of class II alleles was visualized through Neighbour-Net networks that were built in the software SPLITSTREE 4 (Huson \& Bryant 2006) using maximumlikelihood distances. In this respect, phylogenetic networks are believed to provide a useful representation of the genetic relationships among sequences when recombination is operating as compared to traditional phylogenetic trees. Finally, isolation by distance was investigated through Mantel tests that were carried out in the program GENETIX 4.04. After introducing a matrix containing both genetic and demographic data, $P$ values were calculated using 10000 permutations. Geographical distance was calculated according to a straight line connecting each pair of sampled populations.

\section{Results}

Genetic diversity at nine microsatellite loci, mtDNA-CR sequences and Fana-DAB*1

We found 103 alleles across nine microsatellite markers and 327 genotyped kestrels. Average observed heterozygosity was 0.66. No significant evidence of linkage disequilibrium was reported between any pair of loci analysed. Only locus Fp107 departed significantly from Hardy-Weinberg expectations and was subsequently removed from further analysis. This locus consistently showed heterozygosity deficits that are likely related to the presence of null alleles (see also Nesje et al. 2000). Six different mtDNA-CR haplotypes were found in 48 lesser kestrels sampled across the Mediterranean (GenBank Accession nos EU525933-EU525938). The polymorphism survey at mtDNA sequences revealed 13 segregating sites corresponding to 13-point mutation events, 5.4 nucleotide differences on average ( 0.41 per site) between unique alleles $(k)$ and a nucleotide diversity ( $\pi$ per site) of 0.021 . At the MHC class 


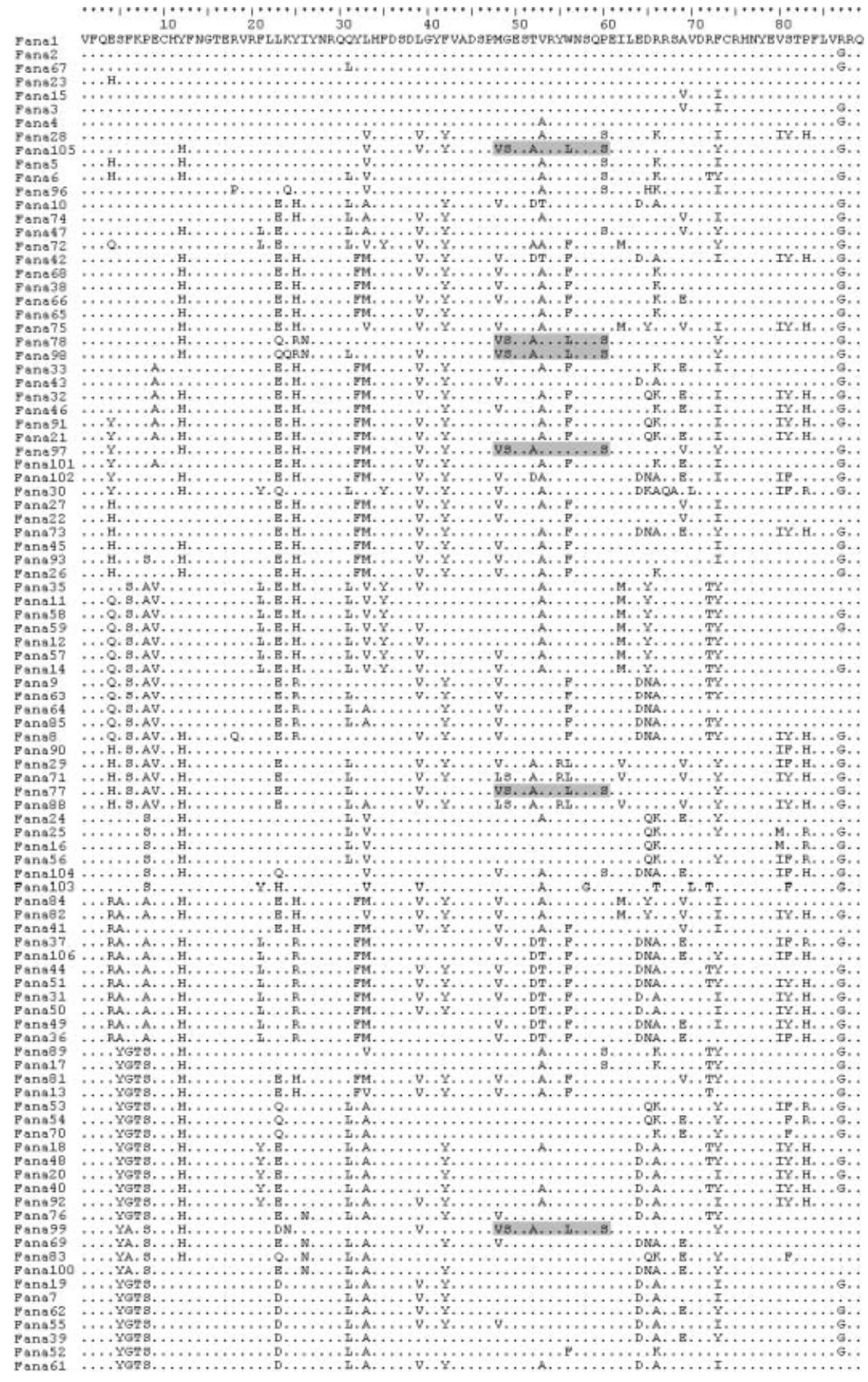

Fig. 2 Inferred amino acid sequences of the Fana-DAB*1 locus. Dots indicate identity with the top sequence. An amino acid motif exclusively found in Kazakhstan is outlined in grey.

II locus Fana-DAB*1, we isolated 103 alleles from 121 kestrels (GenBank Accession nos EF370767-370788 and EU107667-EU107746, see Fig. 2). Average heterozygosity was 0.98 . The polymorphism statistics derived from the analysis of our MHC Class II DR B exon 2 data set revealed 70 variable sites (S), 23.32 nucleotide differences on average ( 0.33 per site) between unique alleles $(k), 85$ nucleotide differences (1.214 per site) between all alleles and a nucleotide diversity among all alleles ( $\pi$ per site) of 0.086. All unique sequences differed by at least one nonsynonymous substitution in the PBR, which suggests that they might also differ in their antigen binding properties. None of the MHC sequences reported here showed any signs of nonfunctionality, such as stop codons or frameshift mutations. We consistently found one or two different MHC alleles per individual. 

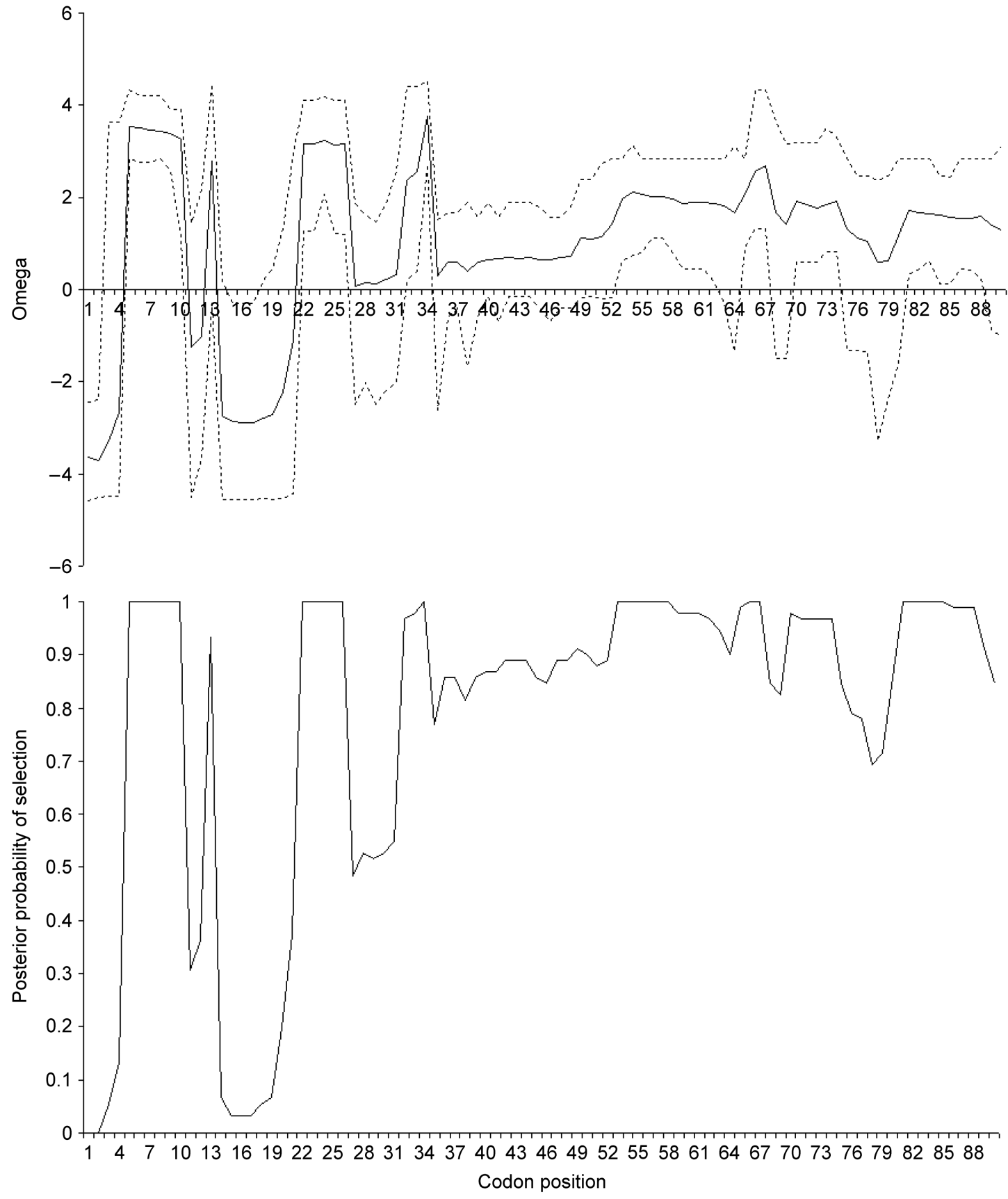

Fig. 3 (a) Spatial variation in the logarithm of the selection parameter $\omega$ across the second exon of a classical MHC class II gene of the lesser kestrel. Parameter estimates were carried out in the software package omEGAMAP using an objective set of prior distributions (Wilson \& McVean 2006). The sitewise mean (solid line) and 95\% HPD intervals (dotted lines) are shown. (b) Spatial variation in the posterior probability of positive selection.

\section{Positive selection and recombination rates at Fana-DAB*1}

Genetic analysis performed in DNASP revealed significant deviations from neutral expectations in the frequency spectrum of segregating sites within the kestrel MHC, with an excess of high frequency sites (Tajima's $D=2.37$, $P<0.05)$. Analyses performed in OMEgAMAP revealed a mean value per codon of $\omega=4.02$. Spatial variation in the selection parameter $\omega$ across exon 2 is represented in Fig. 3 where several amino acid sites display a hallmark of positive selection. The mean amount of population recombination per codon $(\rho=0.389)$ greatly exceeds the mean amount of population mutation $(\theta=0.017)$. These results suggest that the accumulation of new recombinants 
(a)

(b)
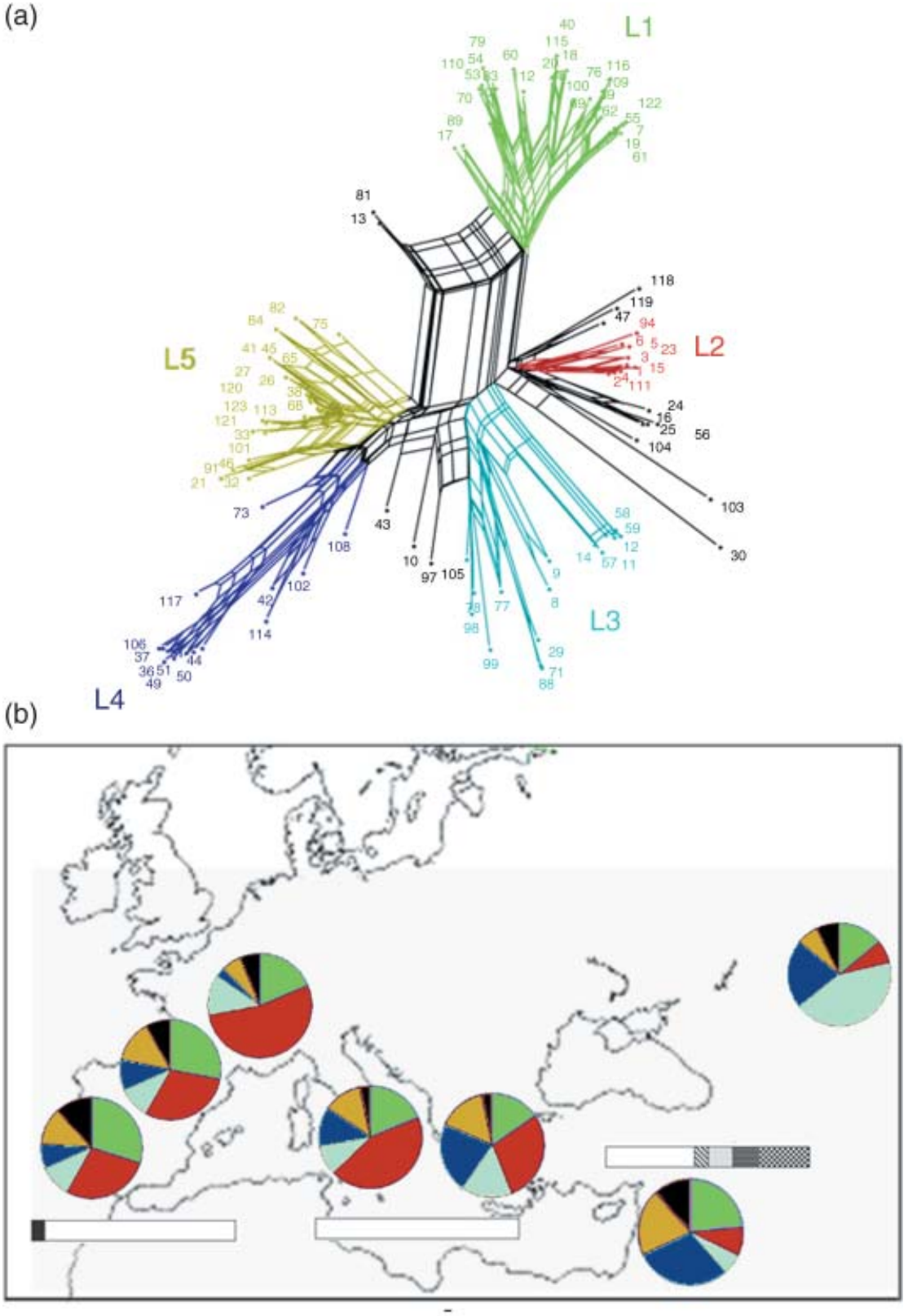

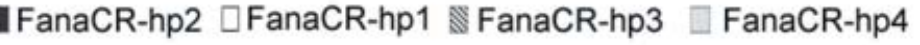

FanaCR-hp5 : FanaCR-hp6

exceeds that of new mutations by at least one order of magnitude. The Neighbour-Net network presented in Fig. 4 also reveals a complex pattern suggesting multiple recombination events during the evolutionary history of the locus.

\section{Patterns of population differentiation at neutral and adaptive loci}

Pairwise estimates of population differentiation at eight microsatellite markers revealed significant evidence of
Fig. 4 (a) Neighbour-Net constructed from exon 2 sequences isolated in the lesser kestrel. Seven allelic lineages are proposed taking into account the clustering of class II sequences and considering the presence of abundant MHC alleles within clusters. (b) Spatial variation in the lesser kestrel MHC (coloured circles) as a means of partial contributions of different allelic lineages. Geographical variation at mtDNA-CR sequences (bars) is also shown. 

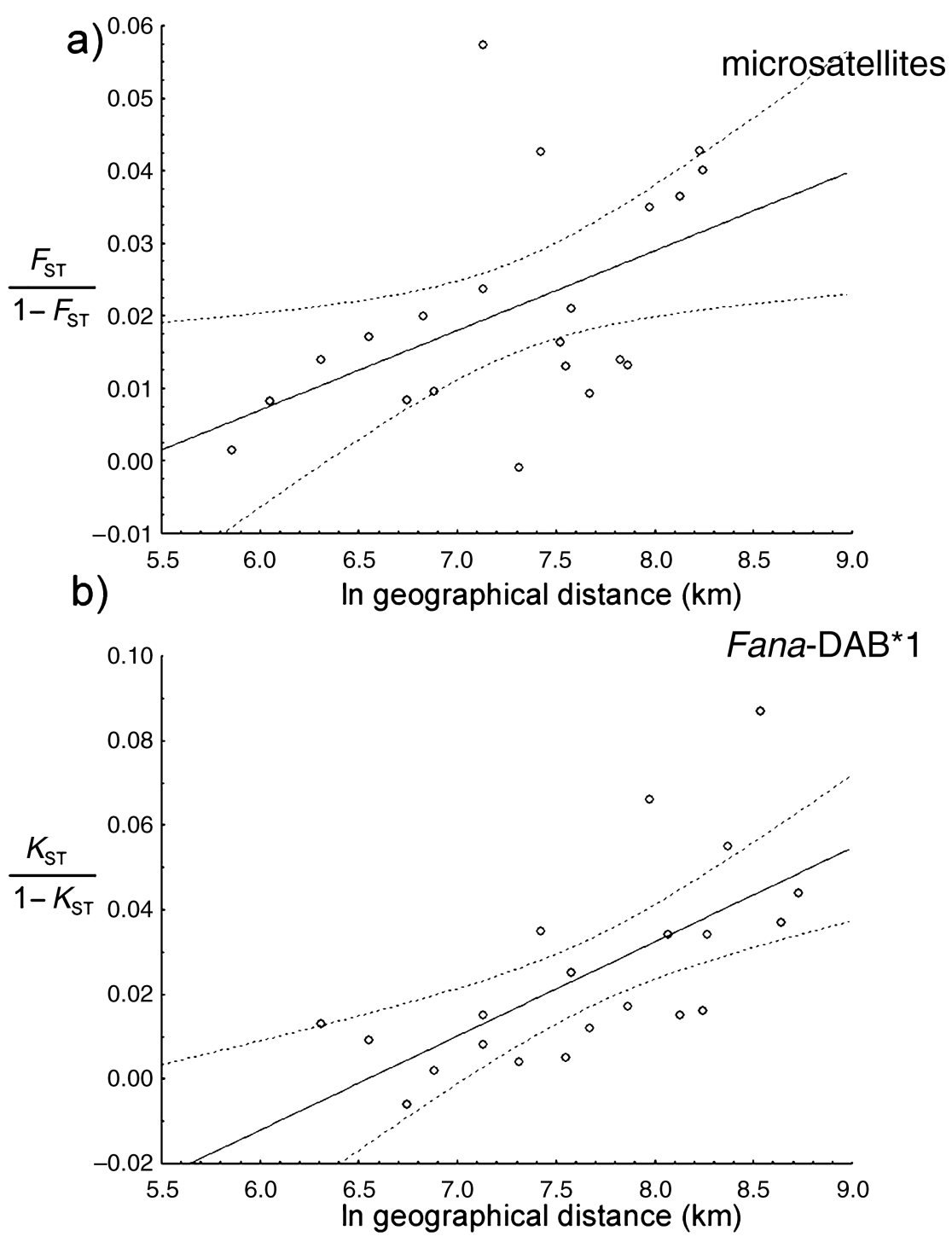

Fig. 5 (a) Correlation between the extent of genetic differentiation at eight microsatellite markers and geographical distance in Mediterranean populations of lesser kestrel $(r=0.50, P=0.04)$. (b) Correlation between the extent of genetic differentiation at Fana$\mathrm{DAB}^{*} 1$ and geographical distance when analysing sampled populations from Spain to Kazakhstan $(r=0.67, \quad P=0.01) .95 \%$ confidence intervals are indicated by dotted lines. with the uniform distribution of allelic frequencies that we found at microsatellites (see Table 1, Figs 4 and 6). For instance, 13 class II sequences isolated from seven kestrels sampled in Kazakhstan were not previously registered in any Mediterranean kestrel. Moreover, we found an exclusively abundant amino acid motif in Kazakhstan (amino acid positions 48-60; see Fig. 2). By contrast, the chance of finding private alleles at high frequencies when analysing microsatellite markers was low (see Fig. 6). Genetic divergence at the MHC fits better into geographical variation at mitochondrial control region sequences (see Fig. 4). Thus, we found one haplotype uniformly distributed across the Western and Central Mediterranean that was also abundant in the most distant Mediterranean population of Israel. Nevertheless, we found in Israel new haplotypes not previously reported in European populations that might represent Asian haplotypes. The $K_{\mathrm{ST}}$ estimate for $\mathrm{CR}$ sequences between the most distant Mediterranean populations of Spain and Israel was $0.17(P<0.05)$.

\section{Discussion}

Ours is one of the first studies examining MHC diversity in wild populations of a bird of prey. We have reported exceptionally high levels of polymorphism at a putatively functional and expressed MHC class II locus in the lesser kestrel, Fana-DAB*1. Analysis of the entire second exon revealed no stop codons or frameshift mutations as well as genetic evidence for balancing selection and recombination. 

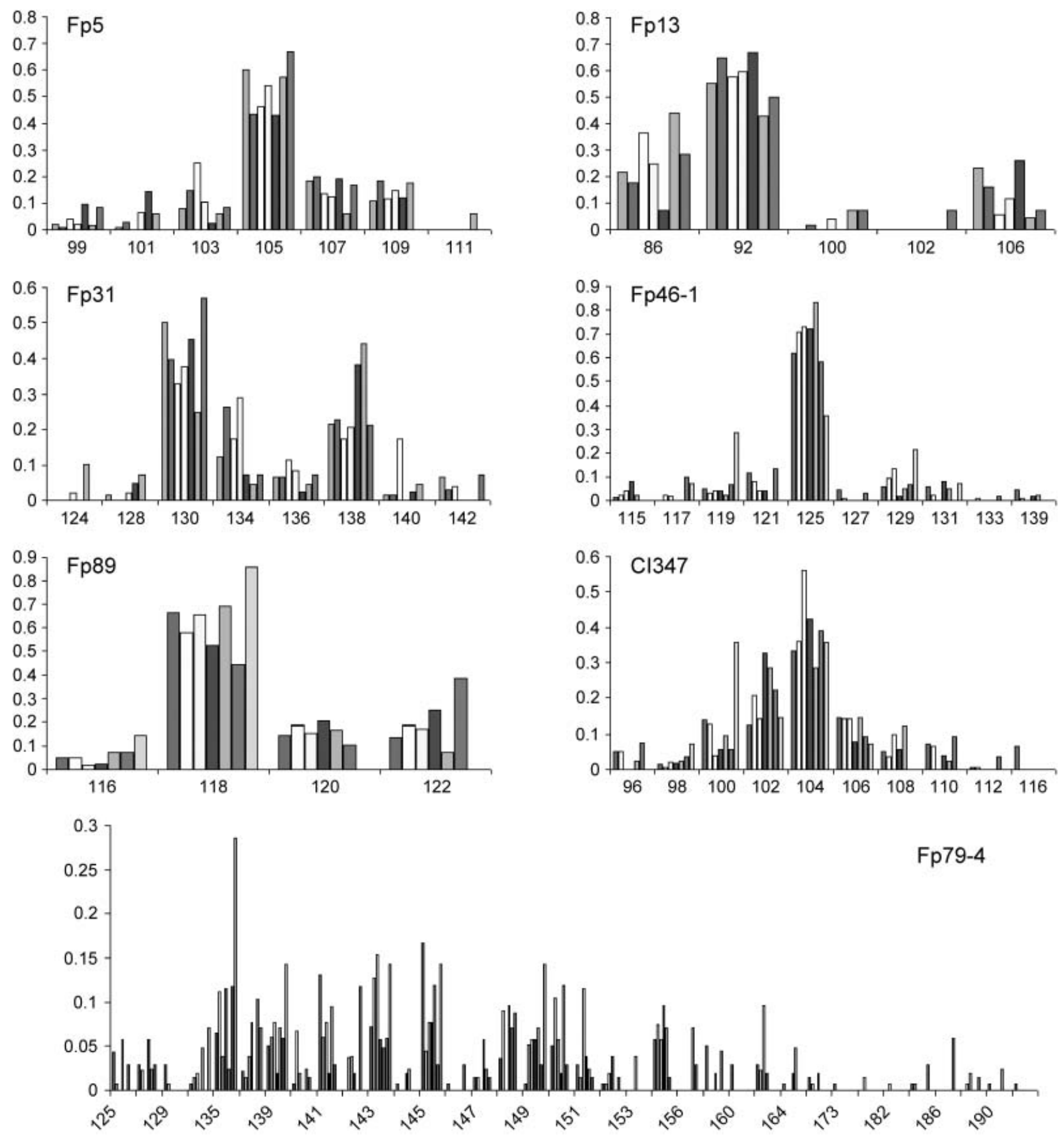

Fig. 6 Distribution of allelic frequencies at seven polymorphic microsatellite markers in the lesser kestrel. Sampled populations follow a western-eastern direction (left-SWS-NES-FRA-ITA-GRE-ISR-KAZ-right, Fig. 1). Allele size in bp is given in the $x$ axis.

Whereas Bayesian analysis of diversifying selection in the presence of recombination seems to be more conservative than maximum-likelihood methods (see Alcaide et al. 2007 for a comparison), several amino acid sites of exon 2 were shown to have experienced strong positive selection (Fig. 3). Although we have not performed gene expression analysis, research in this topic has observed a strong correlation between signatures for balancing selection and expression (e.g. Zoorob et al. 1990; Jacob et al. 2000). In addition, whereas many studies in birds have been unable to examine allelic diversity at a single MHC locus (Edwards et al. 1998; Hess et al. 2000; Bonneaud et al. 
2004), or have encountered low polymorphism at MHC loci (Hess et al. 2000; Gasper et al. 2001; Aguilar et al. 2006), we have been able to focus exclusively on variation at a single highly polymorphic MHC locus. In fact, the level of expression and functional relevance of different loci, as well as locus identity of alleles is unknown in many bird studies (i.e. Edwards et al. 1998; Hess et al. 2000; Bonneaud et al. 2004), making appropriate population genetic analyses difficult. Hence, the specific amplification of a single locus exhibiting strong positive selection may turn the lesser kestrel into an excellent model species for the investigation of the evolutionary significance of MHC genes and its relationship to adaptive variation. The amplification of one single locus in this species is also supported by an ongoing study in which the segregation of MHC alleles from parents to the offspring is fitted to a single model of biparental inheritance. Hence, we found some homozygous genotypes in the offspring when the parents shared at least one allele (M. Alcaide, J. J. Negro, D. Serrano, unpublished data). At the very least, MHC allelic composition and heterozygosity at the genomic level can therefore be readily tested in detail in kestrels and related species (for instance, in relation to resistance/susceptibility to parasite infections and other fitness-related traits such as reproductive performance). The role of heterozygosity at the MHC has been rarely documented in natural populations in detail (e.g. Hedrick et al. 2001; Arkush et al. 2002; Froeschke \& Sommer 2005), although experiments in mice under laboratory conditions are exemplary in this regard (Penn et al. 2002).

Both microsatellite markers and the MHC locus Fana$\mathrm{DAB}^{*} 1$ revealed an isolation-by-distance pattern in our study area that would be in agreement with population fragmentation and with apparently limited dispersal abilities in the philopatric lesser kestrel (Negro et al. 1997; Serrano et al. 2001; Serrano \& Tella 2003). Nonetheless, the lack of private alleles at high frequencies across microsatellites contrasts with the pronounced differences in the frequencies of MHC alleles or allelic lineages between European and Asian populations (see Figs 4 and 6). Such genetic divergence may be consequence of historically limited gene flow among both areas, a fact that is supported by preliminary mitochondrial data in the form of cytochrome $b$ sequences (Wink et al. 2004) as well as by our control region sequences (Fig. 4). On the other hand, it is perhaps not surprising that the microsatellite loci showed uniformly lower levels of differentiation than Fana-DAB*1. These two sets of loci differ not only in selective regimes but also in mechanism of mutation, with microsatellites showing levels of variation that many have argued can compromise studies of even closely related populations. Back-mutation and homoplasy can be common in microsatellite alleles, and the high variation within population can result in artificially low levels of population divergence (e.g. Charlesworth 1998). Thus, direct comparison of population patterns of microsatellites and MHC is ultimately complicated by their very different mechanisms of evolution. A more appropriate comparison would be, for example, Fana-DAB ${ }^{*} 1$ with anonymous loci or introns, which, like the MHC, are genotyped by sequencing and evolve primarily by point mutation. Such a study would better identify the true causes of differences between MHC and the neutral portion of the lesser kestrel genome. The contrast in $K_{\mathrm{ST}}$ values between $\mathrm{CR}$ sequences and the Fana-DAB*1 locus after comparing the two distributional borders in the Mediterranean (0.17 vs. 0.015) is instructive in this regard. Accordingly to the equation $K_{\mathrm{ST}}=1 / 1+4 \mathrm{Nm}$, we expect $K_{\mathrm{ST}}$ for mitochondrial sequences to be four times higher than for a nuclear gene since the population size of the former is one-fourth of the latter. Nonetheless, our results suggest that fixation rates in $\mathrm{CR}$ sequences are at least one order of magnitude higher than those reported for MHC coding sequences. These results should be explained in part because balancing selection at the MHC may have mitigated the effects of genetic drift (but see for instance Miller \& Lambert 2004a when dealing with small populations).

Restricted gene flow is a crucial condition to favour local adaptation, and therefore, spatial variation in parasite selection regimes may cause MHC polymorphism in accordance with the hypothesis of Hill (1991; see also Hedrick 2002). Recently, Ekblom et al. (2007) explained spatial patterns of MHC class II variation in the great snipe Gallinago media as a result of local adaptation to different ecologically distinct distributional regions (i.e. mountain populations vs. lowland populations). By contrast, lesser kestrels are known to inhabit similar steppes and pseudosteppes ecosystems across Eurasia (Cramp \& Simmons 1980; Ferguson-Lees \& Christie 2001), and our results would be better explained attending to limited gene flow translated into different adaptations to local pathogen communities as an example of geographically varying co-evolution (see Thompson 2005). In this sense, several studies have shown that the degree of population structure of parasites is related to that of the host species exploited (e.g. Blouin et al. 1995; Criscione \& Blouin 2007), while others have documented situations in which the host displayed low genetic differentiation but parasite populations were strongly structured (e.g. McCoy et al. 2005).

Finally, strong geographical variation at the MHC suggests the potential of locally selected MHC alleles or allelic lineages to resolve the origin of captive or vagrant individuals. The lesser kestrel has a direct implication in this regard, since knowledge about the composition of the different wintering grounds in Africa is of high relevance in conservation. Hence, MHC alleles could be used in combination with mtDNA to unravel migration routes. At the very least, cytochrome $b$ sequences implicated South Africa as an important wintering ground of Asian populations, 
with no trace for European birds (Wink et al. 2004). Nevertheless, Wink and coworkers found some degree of haplotype mixing in both breeding and wintering populations, and at this point, MHC alleles may improve assignment of individuals. In the same line, our CR sequences give no resolution in European populations and shared haplotypes have been found in Israel. Since the intronic sequences flanking the second exon of the class II B genes are highly conserved at the family level (Alcaide et al. 2007), this highly polymorphic region can be successfully cross-amplified in a large variety of species as a means of obtaining fast and valuable genetic information. Moreover, the size of the amplified fragment (about $300 \mathrm{bp}$ ) would allow the investigation of noninvasive samples involving degraded DNA.

\section{Acknowledgements}

We are indebted to all the people who kindly provided the kestrel samples. Therefore, we are thankful to E. Ursúa, A. Gajón, M. de la Riva, P. Pilard, L. Brun J, M. Visceglia, R. Blachos and A. Gal. This study was supported by the MEC of the Spanish government (project CGL2004-04120) and the CSIC, which also provided research grants to $\mathrm{M}$. Alcaide.

\section{References}

Aguilar A, Roemer G, Debenham S, Binns M, Garcelon D, Wayne RK (2004) High MHC diversity maintained by balancing selection in an otherwise genetically monomorphic mammal. Proceedings of the National Academy of Sciences, USA, 101, 3490-3494.

Aguilar A, Edwards SV, Smith TB, Wayne RK (2006) Patterns of variation in MHC class II B loci of the little greenbul (Andropadus virens) with comments on MHC evolution in birds. Journal of Heredity, 97, 133-142.

Alcaide M, Negro JJ, Serrano D, Tella JL, Rodríguez C (2005) Extrapair paternity in the lesser kestrel Falco naumanni: a re-evaluation using microsatellite markers. Ibis, 147, 608-611.

Alcaide M, Edwards SV, Negro JJ (2007) Characterization, polymorphism and evolution of MHC class II B genes in birds of prey. Journal of Molecular Evolution, 65, 541-554.

Anisimova M, Nielsen R, Yang Z (2003) Effect of recombination on the accuracy of the likelihood method for detecting positive selection at amino acid sites. Genetics, 164, 1229-1236.

Arkush KD, Giese AR, Mendonca HL, McBride AM, Marty GD, Hedrick PW (2002) Resistance to three pathogens in the endangered winter-run Chinook salmon (Oncorhynchus tshawytscha): effects of inbreeding and major histocompatibility complex genotypes. Canadian Journal of Fisheries Aquatic Sciences, 59, 966-975.

Belkhir K, Borsa P, Chikhi L, Raufaste N, Bonhomme F (1996-2002) GeNetix 4.04 Logiciel sous Windows, pour la Génétique des Populaions. Laboratoire Génome, Populations, Interactions, CNRS UMR 5000, Université de Montpellier II, Montpellier, France.

Bernatchez L, Landry C (2003) MHC studies in nonmodel vertebrates: what have we learned about natural selection in 15 years? Journal of Evolutionary Biology, 16, 363-377.

Biber JP (1990) Action Plan for the Conservation of Western Lesser Kestrel (Falco naumanni) Populations. International Council for Bird Preservation (Study Report 41), Cambridge, UK.
Blouin MS, Yowell CA, Courtney CH, Dame JB (1995) Host movement and the genetic structure of populations of parasitic nematodes. Genetics, 141, 1007-1014.

Bollmer J, Hernán Vargas F, Parker PG (2007) Low MHC variation in the endangered Galapagos penguin (Spheniscus mendiculus). Immunogenetics, 59, 593-602.

Bonneaud C, Pérez-Tris J, Federici P, Chastel O, Sorci G (2006) MHC alleles associated with local resistance to malaria in a passerine. Evolution, 60, 383-389.

Bonneaud C, Sorci G, Morin V, Westerdahl H, Zoorob R, Wittzell H (2004) Diversity of $M H C$ class I and IIB genes in house sparrows (Passer domesticus). Immunogenetics, 55, 855-865.

Bos DH, DeWoody JA (2005) Molecular characterization of major histocompatibility complex class II alleles in wild tiger salamanders (Ambystoma tigrinum). Immunogenetics, 57, 775-781.

Bradley RD, Hillis DM (1996) Recombinant DNA sequences generated by PCR amplification. Molecular Biology and Evolution, 14, 592-593.

Charlesworth B (1998) Measures of divergence between populaions and the effect of forces that reduce variability. Molecular Biology and Evolution, 15, 538-554.

Clarke B, Kirby DR (1966) Maintenance of histocompatibility polymorphisms. Nature, 222, 999-1000.

Coltman DW, Slate J (2003) Microsatellite measures of inbreeding: a meta-analysis. Evolution, 57, 971-983.

Cramp S, Simmons KEL (1980) The Birds of the Western Palearctic, Vol. 2. Oxford University Press, Oxford, UK.

Crandall KA, Bininda-Emonds ORP, Mace GM, Wayne RK (2000) Considering evolutionary processes in conservation biology. Trends in Ecology \& Evolution, 17, 390-395.

Criscione CD, Blouin MS (2007) Parasite phylogeograhical congruence with salmon host evolutionary significant unit: implications for salmon conservation. Molecular Ecology, 16, 993-1005.

DeWoody YD, DeWoody JA (2005) On the estimation of genomewide heterozygosity using molecular markers. Journal of Heredity, 96, 85-88.

Edwards SV, Dillon M (2004) Hitchhiking and recombination in birds: evidence from MHC-linked and unlinked loci in redwinged blackbirds (Agelaius phoeniceus). Genetical Research, 84, 175-192.

Edwards SV, Hedrick PW (1998) Evolution and ecology of MHC molecules: from genomics to sexual selection. Trends in Ecology E Evolution, 13, 305-311.

Edwards SV, Grahn M, Potts WK (1995) Dynamics of MHC evolution in birds and crocodilians: amplification of class II genes with degenerate primers. Molecular Ecology, 4, 719-729.

Edwards SV, Gasper J, Stone M (1998) Genomics and polymophism of Agph-DAB1, an MHC class II B gene in red-winged blackbirds (Agelaius phoenicus) Molecular Biology and Evolution, 15, 236-250.

Ekblom R, Sæxther SA, Jacobson P et al. (2007) Spatial patterns of MHC class II variation in the great snipe (Gallinago media). Molecular Ecology, 16, 1439-1451.

Ferguson-Lees J, Christie DA (2001) Raptors of the World. Houghton Mifflin Co., Boston, Massachusetts.

Fredsted T, Pertoldi C, Schierup MH, Kappeler PM (2005) Microsatellite analyses reveal fine-scale genetic structure in grey mouse lemurs (Microcebus murinus). Molecular Ecology, 14, 2363-2372.

Froeschke G, Sommer S (2005) MHC class II DRB constitution and parasite load in the striped mouse Rhabdomys pumilio, in the Southern Kalahari. Molecular Biology and Evolution, 22, 1254-1259. 
Garrigan D, Hedrick PW (2003) Detecting adaptive molecular polymorphism: lessons from the MHC. Evolution, 57, 1707-1722.

Gasper JS, Shiina T, Inoko H, Edwards SV (2001) Songbird genomics: analysis of $45 \mathrm{~kb}$ upstream of a polymorphic MHC class II gene in red-winged blackbirds (Agelaius phoeniceus). Genomics, 75, 26-34.

Gemmell NJ, Akiyama S (1996) An efficient method for the extraction of DNA from vertebrate tissues. Trends in Genetics, 12, 338-339.

Godoy JA, Negro JJ, Hiraldo F, Donazar JA (2004) Phylogeraphy, genetic structure and diversity in the bearded vulture (Gypaetus barbatus, L.), as revealed by mitochondrial DNA. Molecular Ecology, 13, 371-390.

Hall TA (1999) BIOEDIT: a user-friendly biological sequence alignment editor and analysis program for Windows 95/98/NT. Nucleic Acids Symposium Series, 41, 95-98.

Hedrick PW (1999) Balancing selection and MHC. Genetica, 104, 207-214

Hedrick PW (2002) Pathogen resistance and genetic variation at MHC loci. Evolution, 56, 1902-1908.

Hedrick PW, Kim TJ, Parker KM (2001) Parasite resistance and genetic variation in the endangered Gila topminow. Animal Conservation, 4, 103-109.

Hess CM, Gasper J, Hoekstra HE, Hill CE, Edwards SV (2000) MHC class II pseudogene and genomic signature of a 32-kb cosmid in the house finch (Carpodacus mexicanus). Genome Research, 10, 613-623.

Hill AVS (1991) HLA association with malaria in Africa: some implications for MHC evolution. In: Molecular Evolution of the Major Histcompatibility Complex (eds Klein J, Klein D), pp. 403-419. Springer, Berlin and Heidelberg.

Hill AVS (1998) The immunogenetics of human infectious diseases. Annual Reviews of Immunology, 16, 593-617.

Hudson RR, Slatkin M, Maddison WP (1992) Estimation of levels of gene flow from DNA sequence data. Genetics, 132, 583-589.

Hughes AL (1991) MHC polymorphism and the design of captive breeding programs. Conservation Biology, 5, 249-251.

Hughes AL, Nei M (1992) Maintenance of MHC polymorphism. Nature, 355, 402-403.

Huson H, Bryant D (2006) Application of phylogenetic networks in evolutionary studies. Molecular Biology and Evolution, 23, 254-267.

Jacob JP, Milne S, Beck S, Kaufman J (2000) The major and a minor class II beta-chain (B-LB) gene flank the Tapasin gene in the B-F/B-L region of the chicken major histocompatibility complex. Immunogenetics, 51, 138-147.

Jarvi SI, Tarr CL, McIntosh CE, Atkinson CT, Fleischer RC (2004) Natural selection of the major histocompatibility complex (MHC) in Hawaiian honeycreepers (Drepanidinae). Molecular Ecology, 13, 2157-2168.

Kaufman J, Salomonsen J (1997) The 'minimal essential MHC' revisited: both peptide-binding and cell surface expression level of MHC molecules are polymorphisms selected by pathogens in chickens. Hereditas, 127, 67-73.

Klein J (1986) Natural History of the Major Histocompatibility Complex. Wiley \& Sons, New York.

Klein J, Bontrop RE, Dawkins RL et al. (1990) Nomenclature for the major histocompatibility complexes of different species: a proposal. Immunogenetics, 31, 217-219.

Lund O, Nielsen M, Kesmir C, Petersen AG, Lundegaad C, Worning P, Sylvester-Hvid C, Lamberth K, Røder G, Justesen S, Buus S,
Brunak S (2004) Definition of supertypes for HLA molecules using clustering specific matrices. Immunogenetics, 55, 797-810.

Martínez-Cruz B, Godoy JA, Negro JJ (2004) Population genetics after fragmentation: the case of the endangered Spanish imperial eagle (Aquila adalberti). Molecular Ecology, 13, 2243-2255.

McCoy KD, Boulinier T, Tirard C (2005) Comparative hostparsite population structures: disentangling prospecting and dispersal in the black-legged kittiwake Rissa tridactyla. Molecular Ecology, 14, 2825-2838.

Miller HC, Belov K, Daugherty CH (2005) Characterization of MHC class II genes from an ancient reptile lineage, Sphenodon (tuatara). Immunogenetics, 57, 883-891.

Miller KM, Kaukinen KH, Beacham TD, Withler RE (2001) Geographic heterogeneity in natural selection on an MHC locus in sockeye salmon. Genetica, 111, 237-257.

Miller HC, Lambert DM (2004a) Genetic drift outweighs balancing selection in shaping post-bottleneck major histocompatibility complex variation in New Zealand robins (Petroicidae). Molecular Ecology, 13, 3709-3721.

Miller HC, Lambert DM (2004b) Gene duplication and gene conversion in class II MHC genes of New Zealand robins (Petroicidae). Immunogenetics, 56, 178-191.

Miller KM, Whitler RE (1997) MHC diversity in Pacific salmon: population structure and trans-species allelism. Hereditas, 127, 83-95.

Miller KM, Whitler RE, Beacham TD (1997) Population differentiation at MHC genes in chinook salmon Oncorhynchus tshawytscha. Molecular Ecology, 6, 937-954.

Musolf K, Meyer-Lucht Y, Sommer S (2004) Evolution of MHCDRB class II polymorphism in the genus Apodemus and a comparison of DRB sequences within the family Muridae (Mammalia: Rodentia). Immunogenetics, 56, 420-426.

Negro JJ, Hiraldo F, Donazar JA (1997) Causes of natal dispersal in the lesser kestrel: inbreeding avoidance or resource competition? Journal of Animal Ecology, 66, 640-648.

Nesje M, Roed KH, Lifjeld JT, Lindberg P, Steens OF (2000) Genetic relationship in the peregrine falcon (Falco peregrinus) analysed by microsatellite DNA markers. Molecular Ecology, 9, 53-60.

Nittinger F, Gamauf A, Pinsker W, Wink M, Haring E (2007) Phylogeography and population structure of the saker falcon (Falco cherrug) and the influence of hybridization: mitochondrial and microsatellite data. Molecular Ecology, 16, 1497-1151.

Paetkau D, Calvert W, Stirling I, Strobeck C (1995) Microsatellite analysis of population structure in Canadian polar bears. Molecular Ecology, 4, 347-354.

Penn DJ, Damjanovich K, Potts WK (2002) MHC heterozygosity confers a selective advantage against multiple-strain infections. PNAS, 99, 11260-11264.

Penn DJ, Potts WK (1999) The evolution of mating preferences and major histocompatibility genes. American Naturalist, 153, 145-164.

Piertney SB (2003) Major histocompatibility complex B-LB gene variation in red grouse, Lagopus lagopus scoticus. Wildife Biology, 9, 251-259.

Piertney SB, Oliver MK (2006) The evolutionary ecology of the major histocompatibility complex. Heredity, 96, 7-21.

Raymond M, Rousset F (1995) GENEPOP (version 1.2): population genetics software for exact tests and ecumenicism. Journal of Heredity, 86, 248-249.

Richman A, Herrera LG, Nash D, Schierup MH (2003) Relative roles of mutation and recombination in generating allelic 
polymorphism at MHC class II locus in Peromyscus maniculatus. Genetical Research, 82, 89-99.

Robinson J, Malik A, Parham P, Bodmer JG, Marsh SGE (2000) IMGT/HLA database - a sequence database for the human major histocompatibility complex. Tissue Antigens, 55, 280-287.

Rozas J, Sánchez-DelBarrio JC, Messeguer X, Rozas R (2003) DNASP, DNA polymorphism analyses by the coalescent and other methods. Bioinformatics, 19, 2496-2497.

Serrano D, Tella JL (2003) Dispersal within a spatially structured population of lesser kestrel: the role of spatial isolation and conspecific attraction. Journal of Animal Ecology, 72, 400-410.

Serrano D, Tella JL, Forero MG, Donázar JA (2001) Factors affecting breeding dispersal in the facultatively colonial Lesser kestrel: individual experience vs conspecific cues. Journal of Animal Ecology, 70, 568-578.

Sommer S (2005) The importance of immune gene variability in evolutionary ecology and evolution. Frontiers in Zoology, 2, 16.

Tella JL, Forero MG, Hiraldo F, Donázar JA (1998) Conflicts between lesser kestrel conservation and European agricultural policies identified by habitat use analyses. Conservation Biology, 12, 593-604.

Thompson JN (2005) The Geographic Mosaic of Coevolution. University of Chicago Press, Chicago.

Trachtenberg E, Korber B, Sollars C et al. (2003) Advantage of rare HLA supertype in HIV disease progression. Nature Medicine, 9, 928-935.

Wagner A, Blackstone N, Cartwright Pet al. (1994) Surveys of gene families using polymerase chain reaction: PCR selection and PCR drift. Systematic Biology, 43, 250-261.

Wegner KM, Kalbe M, Rauch G, Kurtz J, Schaschl H, Reusch TBH (2006) Genetic variation in MHC class II expression and interactions with MHC sequence polymorphism in three-spined sticklebacks. Molecular Ecology, 15, 1153-1164.

Westerdahl H, Wittzell H, von Schantz T, Bensch S (2004) MHC class I typing in a songbird with numerous loci and high polymorphism using motif-specific PCR and DGGE. Heredity, 92, 534-542.
Wilson DJ, McVean G (2006) Estimating diversifying selection and functional constraint in the presence of recombination. Genetics, 172, 1411-1425.

Wink M, Sauer-Gürth H, Pepler D (2004) Phylogeographic relationships of the lesser kestrel Falco naumanni in breeding and wintering quarters inferred from nucleotide sequences of the mitochondrial cytochrome $b$ gene. In: RD Chancellor \& BU Meyburg (eds), Raptors Worldwide, pp. 505-510. WWGBP/ MME, Berlin.

Witzell H, Bernot A, Auffrey C, Zoorob R (1999) Concerted evolution of two MHC class II B loci in pheasants and domestic chickens. Molecular Biology and Evolution, 16, 479-490.

Yang Z (2000) Phylogenetic Analysis by Maximum Likelihood (PAML), Version 3.0. University College London, London, (http:// abacus.gene.ucl.ac.uk/software/paml.html).

Ye X, Zhu J, Velleman SG, Bacon WL, Nestor KE (1999) Analysis of genetic polymorphism in the major histocompatibility complex of Japanese quail. Poultry Science, 78, 8-14.

Zoorob R, Behar G, Kroemer G, Auffrey C (1990) Organization of a functional chicken class II B gene. Immunogenetics, 31, 179-187.

Miguel Alcaide is interested in the investigation of adaptive genetic variation in vertebrates. Scott Edwards and his lab are interested in the population genetics, comparative genomics and evolution of birds and relatives. Juan José Negro although initially trained as a behavioural ecologist, is also interested in genetic variability issues, hybridization and genetic erosion in small populations. David Serrano is interested in behavioural ecology, demography and population ecology. His main research lines focus of animal dispersal and evolution of avian coloniality. José L. Tella is interested in a variety of evolutionary, behavioural and conservation ecology issues, including the demographic, genetic, physiological and cultural effects of habitat fragmentation on bird populations.

\section{Appendix}

Primer sequences for locus Cl347 (F: TGTGTGTGTAAGGTTGCCAAA; R: CGTTCTCAACATGCCAGTTT) and Cl58 (F: TGTGTCTCAGTGGGGAAAAA; R: TGCTTTGGTGCTGAAGAAAC). 